\title{
ATUAÇÃO DO GESTOR DE PROJETOS EM SITUAÇõES ADVERSAS AO PLANEJADOI
}

\author{
Giuliano Chagas Biasioli2 \\ Maisa Helena Pimenta ${ }^{3}$
}

RESUMO: Este artigo analisa o resultado de uma pesquisa que busca demonstrar a qualidade da tomada de decisões do gestor de projetos em situações adversas ao planejado com base nas premissas do gerenciamento de risco. Explora as maiores dificuldades que o gestor enfrenta quando se vê em um cenário fora do esperado, em situações não previstas como: atrasos no cronograma, mudanças inesperadas pelas partes interessadas (stakeholders) e competências inadequadas. Para tanto, foi realizado um estudo de caso por meio de questionário, para compreender a forma como um gestor de projetos equilibra o gerenciamento de riscos com as suas habilidades pessoais e as de seus recursos. A análise das respostas indicou o quanto é importante um gerenciamento de riscos e um gestor apto para direcionar e se antecipar às adversidades, estando preparado, inclusive, para lidar com o que está fora do planejado. A escolha da equipe, os métodos utilizados, avaliações periódicas e preocupação constante com novas possibilidades de risco sempre planejando respostas em curto ou longo prazo, e mesmo tendo as responsabilidades divididas com outros setores ou recursos, o líder do projeto deve ser o mais preparado para todas as possibilidades. Concluí-se que dominar técnicas, conhecer diversos casos, gerir pessoas e tempo e acima de tudo ter responsabilidade para com seu cronograma e equipe são as principais linhas que os gestores devem seguir, pois são as melhores formas de estar preparado para todas e quaisquer adversidades.

Palavras-chave: Gerente de projetos. Gerenciamento de riscos.3 . Adversidades ao planejamento.

\section{INTRODUÇÃO}

Atualmente questiona-se quem possui maior facilidade em lidar com as adversidades: os novos profissionais, com maior capacidade de inovação e audácia, ou os profissionais com maior experiência, que estão com mais preparo e já passaram por situações que os deixam

\footnotetext{
I Trabalho de conclusão de curso de pós-graduação lato sensu à distância em Gestão de Projetos pela UCDB Universidade Católica Dom Bosco em parceria com o Portal Educação. Santo André, 2014.

2 Graduado em Gestão e Desenvolvimento Web pela UniABC. Analista de planejamento em Call Center. Pós-graduando em Gestão de Projetos pela UCDB. E-mail: giubiasioli@gmail.com.

${ }^{3}$ Orientadora do Trabalho de Conclusão de Curso do curso de pós-graduação lato sensu à distância em Gestão de Projetos pela UCDB - Universidade Católica Dom Bosco.
} 
atentos até para possibilidades que normalmente não são consideradas.

Entendemos que a gestão de projetos precisa de profissionais que tenham um pouco dos dois, a inovação e o preparo, mas como equilibrar estes dois pontos? Podem existir. em uma equipe inúmeros tipos de profissionais, portanto a capacidade de se antecipar ao inesperado não deve ser uma exclusividade dos mais experientes. Para isto existe o gerenciamento de risco, que funciona dentro do gerenciamento de projeto como um plano de antecipação às situações adversas ao planejado, mas para que este gerenciamento funcione bem é necessário que o gestor tenha atenção, senso analítico, capacidade de rápida tomada de decisão e o preparo para todas as possibilidades que vão além de tempo exercendo a profissão.

O gerenciamento de risco entra como um método e ou uma prática que vem atraindo interesse das empresas, afinal é uma maneira de se antecipar aos problemas que podem ocorrer durante a implantação de um projeto, tendo tudo mapeado e as ações planejadas para enfrentar as adversidades previstas podendo-se utilizar recursos da mesma equipe de implantação ou uma equipe apartada para realizar este trabalho de forma exclusiva, priorizando e agindo de forma centralizada nos possíveis riscos.

A pesquisa visava investigar a atuação do gestor de projetos em situações adversas ao planejado. Tendo como objetivo demonstrar a importância da criatividade e da audácia de um gestor de projetos em tais situações adversas. Como hipótese, foi trabalhada a questão de que as habilidades pessoais do gestor, nestas duas características, representam o cenário ideal para o gestor de projetos.

Utilizando as premissas do gerenciamento de risco, foi aplicado um questionário com um gestor de projetos de uma empresa de desenvolvimento de software, com experiênciana adoção de práticas de gestão de riscos e na habilidade de tomada de decisões.

O questionário continha questões que abordavam a opinião do gestor para diversas questões, perpassando as principais habilidades, preocupações e práticas em sua carreira 
como gestor de projetos.

\section{O GERENCIAMENTO DE RISCOS E AS HABILIDADES PESSOAIS}

Segundo o PMBOK (PMI, 2008) - Project Management Body of Knowledge -o gerenciamento dos riscos do projeto inclui os processos de planejamento, identificação, análise, planejamento de respostas, monitoramento e controle de riscos de um projeto e redução da probabilidade e do impacto dos eventos negativos no projeto. O planejamento do gerenciamento de risco somado às habilidades pessoais do gestor é fundamental para a atuação de uma equipe, itens como metodologia, papéis e responsabilidade, orçamento, prazos e categorias de riscos sempre revisadas por parte dos interessados. Planejar é se antecipar, então todas as formas de se preparar para as adversidades devem ser consideradas.

Conforme mostrado por Meyer, Loch e Pich, citados por Junior e Carvalho (2013), existe um aspecto interessante sobre as incertezas, que podem ser classificadas em quatro tipos. Há duas delas que são pontos principais deste estudo:

I) Variabilidade: variações aleatórias, porém previsíveis e controláveis em torno de seus objetivos conhecidos de custo e prazo;

2) Incerteza previsível: uns poucos fatores conhecidos irão afetar o projeto de uma forma imprevisível permitindo, entretanto, que sejam estabelecidos planos de continência para tratar das consequências de seu eventual acontecimento;

3) Incerteza imprevisível: um ou mais fatores significativos que influenciam o projeto não podem ser previstos obrigando a solução de problemas nas ocorrências desses;

4) Caos: fatores completamente imprevisíveis invalidam completamente os objetivos, o planejamento e a abordagem do projeto, obrigando a sua repetida e completa redefinição (grifo nosso).

As incertezas imprevisíveis podem gerar o caos, estes itens entram em situações não previstas no gerenciamento de risco que obrigam o gestor a lidar com adversidades forado esperado e tendo que utilizar todas as habilidades necessárias para correção.

Habilidades pessoais e técnicas para identificar riscos, quando somadas, podem se antecipar para todas as adversidades, porém ainda será necessário estar sempre atento para 
todas as possibilidades e o gestor deve estar apto para rápida ação evitando interferências ainda maiores no projeto.

Entre as principais habilidades pessoais é destacada a liderança como ponto forte,é um dos fatores críticos de sucesso do gerente de projetos (RUSSO, RUIZ E CUNHA, 2005). Um gestor bem preparado para sua posição de líder tem maior facilidade nas tomadas de decisão, sendo extremamente necessária esta influência nos resultados e nos casos de adversidades.

Sendo a liderança o principal processo entre as habilidades pessoais, é esperado que o líder assuma a responsabilidade das tomadas de decisões, principalmente no que ocorre fora do planejado. Para o gerenciamento adequado de um projeto, o PMBOK (PMI, 2008) indica que existem cinco áreas de especialização que a equipe deve entender e usar: conjunto de conhecimentos em gerenciamento de projetos; conhecimento das normas e regulamentos da área de aplicação do projeto; entendimento do ambiente do projeto (cultural, social, internacional, político e físico); conhecimento e habilidades de gerenciamento geral (planejamento, organização, formação e pessoa, etc) e habilidades interpessoais.

As habilidades interpessoais incluem a comunicação eficaz, a influência sobre a organização, a liderança, a motivação, a negociação e o gerenciamento de conflitos e a resolução de problemas (RUSSO, RUIZ E CUNHA, 2005). O último item deixa claro que o líder precisa estar preparado para tudo, se o gerenciamento de riscos não for suficiente, o líder precisa saber exatamente como agir para não colocar em risco todo o projeto, caso ocorra alguma situação adversa daquilo que foi planejado dentro do projeto e de seu gerenciamento de risco.

Segundo Russo e Sbragia (2007), o gerente de projeto, no seu papel de liderança,é um elemento-chave, tanto para o sucesso dos empreendimentos que coordena quanto para a implementação das estratégias da organização. Seguindo esta afirmação é imprescindível que os profissionais da área, principalmente os gestores, estejam preparados para se antecipar 
aos riscos e terem capacidade de rápida tomada de decisão, mesclando a inovação com a experiência.

Além da liderança somada à experiência, outra habilidade que foi citada é a inovação, que é importante neste processo de gerenciamento de riscos e antecipação aos problemas. Instrumento indispensável para o crescimento e sobrevivência no volátil mercado atual, a capacidade de inovação é outro importante fator crítico de sucesso. Inovar, diferentemente de apenas inventar, pressupõe um processo estruturado de estudos técnicos e financeiros até a transformação em aplicações que trarão resultados efetivos para a organização geradora da inovação. Isto é, inovação no meio empresarial é transformação de ideias em negócios (COMPASS, s.d).

Conforme Rovai (2005), muitos projetos, senão a quase totalidade, são gerenciados sem que haja o adequado uso de metodologias e ou modelos de gerenciamento e isto tem causado inúmeras perdas financeiras e de recursos com intensidade e impacto variáveis, porém significativos. Decorre disto a necessidade de um gerenciamento de risco bem estruturado e uma atenção plena sobre as adversidades possíveis durante a implantação de um projeto.

Rovai (2005) cita ainda que inúmeras pesquisas têm apontado para a ausência de um modelo estruturado para gerenciamento de riscos de projeto, por parte das empresas que possuem uma carteira relevante de projetos que não dispõe de modelos e ou metodologias para gestão de riscos de seus projetos.

A criação de um modelo de gerenciamento de riscos bem estruturado para as empresas seria o ideal, tendo como combinação também ideal o diferencial humano de habilidades de tomada de decisão e atenção para todas as possíveis adversidades através do gestor e seus recursos.

Segundo Schuyler, citado por Silva et al (2008), 'risco' é o efeito acumulativo da probabilidade de incerteza que pode afetar positivamente (oportunidade) ou negativamente 
(ameaça) o projeto. Silva comenta ainda que Galway, em vez de buscar respostas para a pergunta "O que é uma boa análise de riscos?", buscou responder o que os usuários do projeto esperam do gerenciamento de riscos. A resposta foi óbvia: precisão (análise qualitativa probabilidade) e auxílio no processo decisório.

O auxílio no processo decisório é essencial em situações adversas ao planejado, considerando que o que foi previsto no gerenciamento de risco esteja dentro daquilo que foi planejado. O líder é o responsável pelo projeto, portanto as decisões são feitas por ele ou passam pelo aval do mesmo.

\section{MÉTODOS DE GERENCIAMENTO DE RISCO}

Dentro de um processo bem estruturado, ainda é possível ocorrer atrasos no cronograma e mudanças inesperadas pelos stakeholders. $\mathrm{O}$ gestor precisa utilizar de todo o planejamento criado e analisar todas as novas situações impostas ou não, suas reais necessidades e através de todas suas habilidades pessoais, encontrar o melhor cenário, sendo oponto chave na decisão tomada pelos envolvidos.

A participação de todas as áreas envolvidas é necessária, de acordo com as premissas da Matriz RACI: envolver quem e qual área for necessário para as tomadas de decisões, pois vão existir situações em que o cliente e o gestor deverão ser os "fiéis da balança" para uma definição, principalmente as de rápido impacto. A Matriz RACI é utilizadapara definir e distribuir as responsabilidades e papéis envolvidos em um processo. É a Matriz indicada pela ITIL para definição de responsabilidades e papéis em um processo. Serve como uma ferramenta que designa quatro responsabilidades para qualquer tipo de processo, tarefa ou atividade (BEZERRA, 20Io). A sigla RACI é o acrônimo para:

- Responsible (Responsável): o responsável pela execução da tarefa;

- $\quad$ Accountable (Responsável): é que possui a propriedade sobre a atividade, e responde pelos seus resultados. Só é possível existir um Accountable. Ele irá responder para oResponsible;

- $\quad$ Consulted (Consultor): Será consultado, fornecendo conselhos, e também 
poderá autorizar determinadas tarefas;

- $\quad$ Informed (Informado): Será informado durante o projeto;

No Exemplo a seguir, de uma forma simples, temos uma Matriz RACI com as responsabilidades de uma equipe (Bezerra, 2010):

Figura 1: Matriz RACI 4

\begin{tabular}{|c|c|c|c|c|}
\hline & Diretor & Gerente & $\begin{array}{c}\text { Analista } \\
\text { SR }\end{array}$ & Financeiro \\
\hline Definir & $\mathrm{I}$ & $\mathrm{R} / \mathrm{A}$ & $\mathrm{C}$ & $\mathrm{I}$ \\
\hline Projetar & $\mathrm{I}$ & $\mathrm{R} / \mathrm{A}$ & $\mathrm{R}$ & $\mathrm{I}$ \\
\hline Desenvolver & $\mathrm{C}$ & $\mathrm{A}$ & $\mathrm{R}$ & $\mathrm{I}$ \\
\hline Testar & $\mathrm{I}$ & $\mathrm{R}$ & $\mathrm{A}$ & $\mathrm{I}$ \\
\hline Implantar & $\mathrm{I}$ & $\mathrm{R}$ & $\mathrm{A}$ & $\mathrm{I}$ \\
\hline
\end{tabular}

Desta maneira, o gestor divide a responsabilidade das tomadas de decisões, agregando maior participação dos envolvidos de acordo com sua responsabilidade, buscando assim as melhores decisões em situações adversas, tanto esperadas pelo gerenciamento de risco, quanto não esperado.

A Matriz RACI não é o único método possível dentro da gestão de projetos e do gerenciamento de risco. Podemos citar algumas de suma importância, tais como:

- Brainstorm: significa tempestade cerebral ou tempestade de ideias (FRAZÃO e CABRAL, [s.d.]). É uma expressão inglesa formada pela junção das palavras "brain", que significa cérebro, intelecto e "storm", que significa tempestade. Brainstormingé um método criado nos Estados Unidos, pelo publicitário Alex Osborn, usado para testar eexplorar a capacidade criativa de indivíduos ou grupos, principalmente nas áreas de relações humanas, 4 Fonte: Disponível em:<https://tecnologiaegestao.wordpress.com/2010/o8/12/matriz-raci/ >. Acesso em
13Abr. 2014. 
dinâmicas de grupo e publicidade e propaganda. A técnica de brainstorming propõe que um grupo de pessoas se reúna e utilize seus pensamentos e ideias para que possam chegar a um denominador comum, a fim de gerar ideias inovadoras que levem um determinado projeto adiante. Nenhuma ideia deve ser descartada ou julgada como errada ou absurda, todas devem estar na compilação ou anotação de todas as ideias ocorridas no processo, para depois evoluir até a solução final.

- Técnica Delhi: trata-se de um questionário interativo, que circula repetidas vezes por um grupo de peritos, preservando-se o anonimato das respostas individuais

(WRIGHT e GIOVINAZZO, [s.d.]). Na primeira rodada os especialistas recebem um questionário, preparado por uma equipe de coordenação, aos quais é solicitado responder individualmente, usualmente com respostas quantitativas apoiadas por justificativas e informações qualitativas. O questionário em geral é bastante elaborado, apresentando para cada questão uma síntese das principais informações conhecidas sobre o assunto, e eventualmente, extrapolações para o futuro, de forma a homogeneizar linguagens e facilitar o raciocínio orientado para o futuro.

As respostas das questões quantitativas são tabuladas, recebendo um tratamento estatístico simples, definindo-se a mediana e os quartis, e os resultados são devolvidos aos participantes na rodada seguinte. Quando há justificativas e opiniões qualitativas associadas a previsões quantitativas, a coordenação busca relacionar os argumentos às projeções quantitativas correspondentes.

A cada nova rodada as perguntas são repetidas, e os participantes devem reavaliar suas respostas à luz das respostas numéricas e das justificativas dadas pelos demais respondentes na rodada anterior. São solicitadas novas previsões com justificativas, particularmente se estas previsões divergirem das respostas centrais do grupo. Esse processo érepetido por sucessivas rodadas do questionário até que a divergência de opiniões entre especialistas tenha se reduzido a um nível satisfatório, e a resposta da última rodada é 
considerada como a previsão do grupo.

O feedback estabelecido através das diversas rodadas permite a troca de informações entre os diversos participantes e em geral conduz a uma convergência rumo a uma posição de consenso. A evolução em direção ao consenso pode ser mensurada pela relação entre a distância do $\mathrm{I}^{\circ}$ ao $3^{\circ}$ quartil das respostas e o valor da mediana. Em algumas vezes, os respondentes se polarizam em torno de duas ou três posições distintas sem se aproximar de um consenso.

$\mathrm{O}$ anonimato das respostas e o fato de não haver uma reunião física reduzem a influência de fatores psicológicos, por exemplo, os efeitos da capacidade de persuasão, da relutância em abandonar posições assumidas, e a dominância de grupos majoritários em relação a opiniões minoritárias.

- Análise Swot: SWOT é a sigla dos termos ingleses Strengths (Forças), Weaknesses (Fraquezas), Opportunities (Oportunidades) e Threats (Ameaças) que consiste em uma metodologia bastante popular no âmbito empresarial (FRAZÃO e CABRAL, [s.d.]).

A Análise SWOT é uma ferramenta utilizada para fazer análise ambiental, sendo à base da gestão e do planejamento estratégico numa empresa ou instituição. Graças à sua simplicidade pode ser utilizada para qualquer tipo de análise de cenário, desde a criação de um blog à gestão de uma multinacional. Este é o exemplo de um sistema simples destinado a posicionar ou verificar a posição estratégica da empresa/instituição no ambiente em questão.

As informações referidas abaixo devem ser enquadradas nas categorias SWOT para análise docenário da empresa: 
1. Strengths (forças) - vantagens internas da empresa em relação às concorrentes. Ex.: qualidade do produto oferecido, bom serviço prestado ao cliente, solidez financeira, etc.

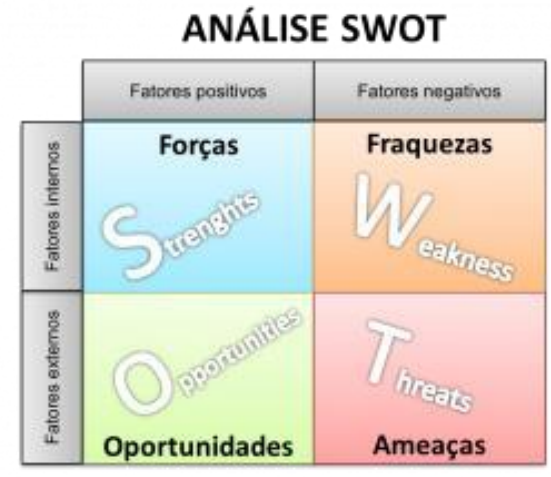

Figura 2: Análise Swot 5

2. Weaknesses (fraquezas) - desvantagens internas da empresa em relação às concorrentes. Ex.: altos custos de produção, má imagem, instalações inadequadas, marca fraca, etc.;

3. Opportunities (oportunidades) - aspectos externos positivos que podem potenciar a vantagem competitiva da empresa. Ex.: mudanças nos gostos dos clientes, falênciade empresa concorrente, etc.;

4. Threats (ameaças) - aspectos externos negativos que podem por em risco a vantagem competitiva da empresa. Ex.: novos competidores, perda de trabalhadores fundamentais, etc.

\section{RESULTADOS E DISCUSSÃO}

O sujeito foi abordado de forma objetiva, respondendo se através das melhores práticas já seria possível mapear grande parte das adversidades e qual a melhor maneira que o mesmo encontrou para identificá-las. O retorno à questão foi direto: "não é possível prever

\footnotetext{
${ }^{5}$ Fonte: Disponível em: <http://www.significados.com.br/swot/>. Acesso em 13 Abr. 201.
} 
todas as adversidades que teremos no desenvolvimento de um projeto". No entanto, o gestor citou que a utilização das melhores práticas, utilizando o guia PMBOK, reduz a possibilidade de que um acontecimento não previsto atrase ou prejudique o projeto e que a leitura constante do PMBOK é uma linha contínua de aprendizado e preparação para estas situações.

No PMBOK (PMI, 2008) é mostrado que o objetivo deste guia é a aplicação de conhecimento, processos, habilidades, ferramentas e técnicas adequadas que podem ter impacto significativo no sucesso de um projeto. O guia $\mathrm{PMBOK}$ identifica esse subconjunto de conhecimento em gerenciamento amplamente reconhecido como boa prática. “Amplamente reconhecido" significa que o conhecimento e as práticas descritas são aplicáveis à maioria dos projetos na maior parte do tempo e que existe um consenso em relação ao seu valor e sua utilidade. "Boa prática" significa que existe um consenso geral de que a aplicação correta dessas habilidades, ferramentas e técnicas pode aumentar as chances de sucesso em uma ampla gama de projetos. Portanto é totalmente válido estudar constantemente o guia, e uma das melhores práticas citadas no mesmo é o Gerenciamento de Risco.

Sobre a adoção do gerenciamento de risco, o sujeito citou que a adoção desta prática aumenta consideravelmente o sucesso do projeto e a antecipação para as adversidades possíveis durante o ciclo de vida do mesmo, pois mantém, tanto gerente quanto equipe, atentos para estas possibilidades e preparados para as decisões necessárias.

Mesmo com uma gestão de risco aplicada ainda existe probabilidade de enfrentar adversidades fora do planejado; no PMBOK, o gerenciamento de risco visa reduzir a probabilidade dos impactos dos eventos negativos, e não a saná-los. Segundo o sujeito, nem sempre os riscos trazem resultados negativos, pois em alguns casos a ocorrência de um risco pode gerar novas ideias para os stakeholders, podendo ser vantajoso e colabor de uma forma positiva. Em um caso citado pelo sujeito também foi possível ver outro lado positivo na 
ocorrência de adversidades: elas colaboram com o desenvolvimento dos recursos e ajudam a atualizar as possibilidades mapeadas para futuros projetos.

A utilização de um gestor específico para gerenciar os riscos pode ser visto como uma excelente maneira de se antecipar às adversidades, deixando um gestor voltado para estas possibilidades. Nesta situação foi possível identificar que a utilização de um gestor específico para riscos está totalmente ligada ao tamanho e ao volume de demandas de um projeto, pois quanto maior a complexidade, maior a necessidade de ter alguém focado neste planejamento.

Quando questionado sobre a escolha da equipe e a atribuição de responsabilidades, já visando à redução dos riscos foi possível identificar a importância da capacidade de liderança e influência de um gestor, pois a necessidade de analisar o perfil e entrevistar os possíveis membros da equipe é essencial. Segundo McGregor, citado porRusso, Ruiz e Cunha (2005), há pelo menos quatro componentes no contexto da liderança:

1. Líder: características do líder, suas motivações, competências e estilo.

2. Liderados: atitudes, necessidades, motivações e outras caracterizam pessoas dosliderados.

3. Tarefa ou Missão: características da organização, como sua proposta, sua estrutura e a natureza das tarefas a serem executadas.

4. Conjuntura: o ambiente social, econômico e político.

É esperado do líder que o mesmo atue de forma coesa na estruturação de equipe, alinhando o perfil de cada recurso com cada item do projeto. O entrevistado citou que quanto maior a experiência com gestão de pessoas, maior a facilidade em abordar corretamente os candidatos às vagas da equipe e uma má avaliação pode comprometer o resultado do projeto. Em um projeto liderado pelo entrevistado, o mesmo recebeu uma equipe já selecionada, pois ocorreu uma troca do gestor de projeto devido a um grande atraso no cronograma. A partir dasprimeiras reuniões foi possível identificar que havia recursos que estavam claramente atuandoem papéis invertidos às suas faculdades. Após ajustes, tudo voltou a caminhar dentro 
do previsto em seu cronograma ocorrendo, inclusive, a entrega antecipada do projeto.

Uma má distribuição de papéis é um risco que deve ser previsto e sempre tratado antes do início de um projeto, pois cabe ao gestor analisar e se antecipar a este tipo de adversidade. Tal situação, além de atrasar e comprometer o cronograma estabelecido prejudica a relação líder versus liderado. Russo, Ruiz e Cunha citam que Bennis identifica quatro competências e habilidades no gerenciamento e liderança, com ênfase ao Gerenciamento da confiança como ponto a se considerar no caso citado polo entrevistado:

- Gerenciamento da atenção: capacidade do líder de fixar atenção, a visão ou a direção no senso dos objetivos, metas e estratégias do projeto;

- Gerenciamento do significado: responsabilidade do líder de comunicar o significado do resultado do projeto dentro da estratégia corporativa;

- Gerenciamento da confiança: um líder deve ser confiável. Os membros da equipe seguirão $\mathrm{m}$ líder com quem sabem que podem confiar, mesmo que estejam em desacordo com seu ponto de vista;

- Gerenciamento de si mesmo: esse gerenciamento é crítico. Se a pessoa está motivada e tem conhecimento e habilidades, haverá uma boa chance de empregá-la de uma maneira efetiva.

Com base nestas informações sobre a escolha de equipe, a possibilidade dos riscos surgirem devido à má distribuição de atividades de recursos ou uma escolha errada de um profissional pode acarretar em diversos infortúnios. O sujeito alega que, quando se fala em gerenciamento de risco, selecionar pessoas é uma das tarefas mais difíceis, sendo que a principal linha a se seguir é a seleção de diversos tipos de recursos. Estes tipos de recursos sãorelacionados ao histórico de cada profissional, desde aquele que conhece o negócio da empresa e possui maior experiência até o funcionário novo, que possui menos "vícios" e visãomais ampla sobre as novas tendências. A criatividade do gestor neste ponto é essencial, a equipe deve ser formada de maneira híbrida entre novatos e experientes, e o percentual de 
cada grupo deve variar de acordo com a complexidade do projeto. Neste ponto, o gerente precisa estar atualizado e preparado para possíveis contratempos relacionados às suas escolhase ao total comprometimento em mostrar à equipe a linha a se seguir dentro de todo o ciclo do projeto. Segundo Russo e Sbragia (2007) citando Dinsmore, apesar da responsabilidade pelo desempenho e realização do projeto ser da equipe, a responsabilidade primária é do gerente deprojetos, devendo conhecer e esclarecer as expectativas e os objetivos do projeto a todos os envolvidos. Além do mais, deve assegurar o atendimento desses objetivos, utilizando o gerenciamento básico nas áreas de escopo, tempo, custo, comunicações, recursos humanos, contratos, matérias e risco.

Com uma equipe formada, fica uma questão pertinente sobre tomadas de decisão: o gestor pode tomar decisões sozinho em situações adversas ou não? Analisando os casos passados pelo sujeito, entendemos que não. O gerente do projeto é responsável por fazer com que todas as partes envolvidas cumpram com o planejado; quando ocorre uma adversidade não prevista, cabe ao gestor junto à área mais próxima àquela situação encontrar um melhor caminho para a solução. Qualquer membro da equipe do projeto, principalmente do gerenciamento de risco, pode encontrar a decisão mais correta, mas tudo dentro da análise do gestor do projeto, pois as decisões precisam ser divididas.

Além do gerenciamento de risco, quando questionado sobre o que pode ser feito além de ter esta ação como padrão, foi possível identificar que são necessário reuniões constantes e revisão do mapa de riscos de forma periódica, atualizando com novas possibilidades de adversidades e também retirando outras.

Se for identificado um possível risco fora de todo o planejamento, algo não previsto em nenhum momento, a melhor maneira encontrada para enfrentar esta adversidade pelo gestor é realizando um monitoramento especial e análise periódica para assim evitá-la.

Para equilibrar a entrega do projeto, se identificado um possível risco não previsto, deve-se avaliar o impacto e se necessário atualizar ou indicar de alguma forma esta 
possibilidade no próprio cronograma. Se o risco for de alto impacto, pode ser necessário um replanejamento do projeto, seguindo o plano estabelecido no gerenciamento de riscos e adicionando a nova adversidade.

$\mathrm{Na}$ opinião do gestor, um fator determinante é planejar respostas aos riscos, desenvolvendo opções e ações pra aumentar as oportunidades e reduzir as ameaças. Um gerente de projetos que não se preocupa com o gerenciamento de riscos e as possíveis adversidades acabam atuando à mercê dos fatos e pode perder excelentes oportunidades de ganho no projeto. Sua criatividade e a sua preparação para tomar decisões, ouvindo e discutindo com os demais envolvidos, é uma parte muito importante deste planejamento.

A visão ampla de todas as possibilidades dentro deste planejamento é a base principal para se gerenciar os riscos. O PMI (2008) propôs seis processos de gerenciamento dos riscos: identificação, avaliação qualitativa, avaliação quantitativa, respostas ao risco e acompanhamento e controle. (RABECHINI JUNIOR e CARVALHO, 20I2).

O gestor do projeto é peça fundamental para todas as partes envolvidas, cabe ao mesmo à organização executora para atingir os objetivos do projeto. As ferramentas e técnicasdo gerenciamento de projetos são especificadas por este recurso. Além de conhecer as ferramentas e técnicas, as boas práticas e todas as competências exigidas para a função, o gestor precisa de três características básicas, descritas no PMBOK (PMI, 2008):

1. Conhecimento: Refere-se ao que o gerente de projetos sabe sobre o gerenciamento de projeto,

2. Desempenho: Refere-se ao que o gerente de projetos é capaz de realizar enquanto aplica seu conhecimento em gerenciamento de projetos.

3. Pessoal: Refere-se ao comportamento do gerente de projetos na execução do projeto ou alguma atividade relacionada. A efetividade pessoal abrange atitudes, principais características de personalidade e lideranças; a capacidade de orientar a equipe do projeto ao mesmo tempo em que atinge objetivos e equilibra as restrições do mesmo.

Estas características foram vistas em todas as respostas do sujeito no questionário aplicado: o conhecimento no gerenciamento de projetos foi visto na busca por se atualizar, a 
leitura constante das melhores práticas descritas no PMBOK, a pesquisa em diversos casos deprojetos semelhantes, a interação com outros gestores, a atenção aos pontos principais da empresa e atenção as necessidades dos stakeholders; o desempenho foi visto durante todo o planejamento e implantação do projeto, reavaliar cronogramas, competências inadequadas, métodos, praticas, necessidades entre outras situações fazem com que o gestor busque constantemente dentro de seu desempenho aplicar todo seu conhecimento; dentro do pessoal foi possível analisar o quanto a gestão de pessoas, liderança, empreendedorismo, empatia e aptidões sociais são essenciais para o gestor que gerencia e lidera o projeto.

Um gestor bem preparado e alinhado com todas estas características, independente do tempo exercendo a função, estará apto a montar um gerenciamento de risco bem estruturado, identificando, analisando, planejando as respostas, monitorando e controlando os riscos de um projeto. O objetivo de reduzir a probabilidade e o impacto para caso ocorra um evento negativo deve ser reavaliado periodicamente, buscando preservar os objetivos do projeto: escopo, cronograma, custo e qualidade.

Partes das adversidades fora do planejado podem ser identificadas com uma avaliação periódica da metodologia utilizada para avaliar os riscos, e para caso ocorra um problema antes de uma possível previsão dentro das reavaliações, a atualização e análise constante das necessidades e o foco nos objetivos do projeto é fundamental para as tomadas de decisão do gestor. A ação para corrigir um problema gerado por uma adversidade não prevista não pode interferir nos demais itens do projeto, seu ciclo de vida deve sofrer as mínimas consequências e a equipe precisa estar em constante atenção.

O gestor ao tomar suas decisões dentro do gerenciamento de risco e dentro de um possível risco inesperado, precisa analisar todas as possibilidades, dentro de todas as partes envolvidas para encontrar a melhor solução, um risco não pode gerar outro risco, uma adversidade não pode prejudicar apenas a integridade do projeto, mas também a equipe responsável pelo mesmo. Quando dito que o gestor é o principal recurso, fica claro que sua 
importância, sendo o elo principal entre todas as partes envolvidas e o líder de toda uma implantação se torna aquele que precisa conhecer a fundo a real necessidade do projeto, do solicitante, e da empresa visando à entrega na forma esperada.

\section{CONSIDERAÇÕES FINAIS}

Após o processo de pesquisa foi possível compreender que quanto mais experiência a empresa e seus recursos possuírem, mas assertivo será o seu gerenciamento de risco. Quando o gerenciamento de risco é feito considerando o máximo de adversidades possíveis, menores serão os casos fora do planejado. Para isto o gestor e seus recursos precisam ler constantemente o PMBOK e a maioria dos casos de adversidade ocorridas em outros projetos parecidos para ampliar as possibilidades de riscos no gerenciamento de risco criado para o seu projeto.

Foi possível identificar que não são os anos de experiência e sim a busca constante por se atualizar e se capacitar que define a atuação do gestor em situações adversas ao planejado. $\mathrm{O}$ experiente e o novato possuem as mesmas possibilidades, a atuação do gestor vai de encontro direto com as suas capacidades, não é preciso vivenciar um problema para se antecipar a ele e sim buscar o conhecimento sobre os possíveis problemas, analisando-os para tomar as melhores decisões quando enfrenta-los.

Os resultados da pesquisa indicaram o quanto é importante um gerenciamento de riscos e um gestor apto para direcionar e se antecipar às adversidades, estando preparado, inclusive, para lidar com o que está fora do planejado. A escolha da equipe, os métodos utilizados, avaliações periódicas e preocupação constante com novas possibilidades de risco sempre planejando respostas aos ricos, em curto ou longo prazo. E mesmo tendo as responsabilidades divididas com outros setores ou recursos, o líder do projeto deve ser o mais preparado para todas as possibilidades. Concluímos que dominar técnicas, conhecer diversos casos, gerir pessoas e tempo e acima de tudo ter responsabilidade para com seu cronograma 
e equipe são as principais linhas que os gestores devem seguir, pois são as melhores formas de estar preparado para todas e quaisquer adversidades.

Para futuros trabalhos seria essencial buscar casos em que o gerenciamento de risco e as tomadas de decisões dos gestores em situações inesperadas foram o fator determinante para o andamento ou sucesso de um projeto. Seria importante ampliar o estudo com a visão de mais de um gestor e incluir a visão dos demais stakeholders.

\section{REFERÊNCIAS}

BEZERRA, Luiz. Matriz RACI. Tecnologia e Gestão. I2 Ago. 2010. Disponível em: 〈https://tecnologiaegestao.wordpress.com/2010/o8/12/matriz-raci/>. Acesso em I3 Abr.2014.

COMPASS BUSINESS SCHOOL. Fundamentos de Gerenciamento de Projetos. [s. 1; s.n; s.d]. Disponível em:<http://wikimp.mp.go.gov.br/twiki/pub/EstruturaOrganica/AreaMeio/Superintende ncias/G GI/GestaodeProjetos/CursoCompass/Apostila_Compass_-

_Fundamentos_de_Gerenciamento_de_Projetos.pdf >. Acesso em I9 Mar. 2014. FRAZÃO, Dilva Guimarães. CABRAL, Paulo. (Orgs). Significados. [s. 1; s.n; s.d].Disponível em: 〈http://www.significados.com.br/>. Acesso em I3 Abr. 2014.

PROJECT MANAGEMENT INSTITUTE - PMI. PMBOK - Um Guia do Conjunto de Conhecimentos do Gerenciamento de Projetos. São Paulo : Saraiva, 2008. 4. ed.

RABECHINI JUNIOR, Roque; CARVALHO, Marly Monteiro de. Relacionamento entregerenciamento de risco e sucesso de projetos. Prod., São Paulo, v. 23, n. 3, Set. 2013.

Disponível em 〈http://www.scielo.br/scielo.php?script=sci_arttext\&pid=Soro365132013000300oII\&lng $=$ en $\& n r m=$ iso $>$. Acesso em o6 Nov. 2013.

ROVAI, R. L. Modelo para gestão de riscos em projetos: estudo de múltiplos casos. 2005. Tese (Doutorado) - Escola Politécnica da Universidade de São Paulo, São Paulo. 
Disponívelem <http://www.teses.usp.br/teses/disponiveis/3/3136/tdeoro92006180244/publico/TeseRovai.pdf>. Acesso em 17 Mar. 2014.

RUSSO, Rosária de Fátima Segger Macri; RUIZ, Jose Moreno; CUNHA, Rosana Paulo da. Liderança e influência nas fases da gestão de projetos. Prod., São Paulo, v. I5, n. 3, Dec. 2005. Disponível em $\langle$ http://www.scielo.br/scielo.php?script=sci_arttext\&pid=Soro3$65132005000300007 \& \operatorname{lng}=\mathrm{en} \& \mathrm{nrm}=$ iso $>$. Acesso em o6 Nov. 2013.

RUSSO, Rosária de Fátima Segger Macri; SBRAGIA, Roberto. Tendência empreendedora do gerente: uma análise de sua relevância para o sucesso de projetos inovadores. Gest. Prod.,São Carlos, v. 14, n. 3, Dec. 2007. Disponível em

〈http://www.scielo.br/scielo.php?script=sci_arttext\&pid=Soro4530X2007000300o12\&lng=en\&nrm=iso >. Acesso em o6 Nov. 2013.

SILVA, Carlos Eduardo Sanches da et al. Aplicação do gerenciamento de riscos no processo de desenvolvimento de produtos nas empresas de autopeças. Prod., São Paulo, v.20, n. 2, 2010. Disponível em:

$\langle$ http://www.scielo.br/scielo.php?script=sci_arttext\&pid=Soro3-

65132010000200006\&lng=pt\&nrm=iso $>$. Acesso em I8 Mar. 2014.

WRIGHT, James Terence Coulter; GIOVINAZZO, Renata Alves. DELPHI Umaferramenta de apoio ao planejamento prospectivo. [s. 1; s.n; s.d]. Disponível em:

〈http://www.fundacaofia.com.br/profuturo/Uploads/Documents/Artigos/art5o.htm〉. Acessoem: 13 Abr. 2014 